\title{
Pancreatic solitary fibrous tumor in a toddler managed by pancreaticoduodenectomy: a case report and review of the literature
}

This article was published in the following Dove Press journal:

OncoTargets and Therapy

27 March 2017

Number of times this article has been viewed

\author{
Qingfeng Sheng' \\ Weijue $X u^{\prime}$ \\ Jiangbin Liu' \\ Baiyong Shen ${ }^{2}$ \\ Xiaxing Deng ${ }^{2}$ \\ Yibo Wu' \\ Wei Wu' \\ Shenghua $\mathrm{Yu}^{\prime}$ \\ Xueli Wang ${ }^{3}$ \\ Zhibao Lv'
}

'Department of General Surgery, Shanghai Children's Hospital,

${ }^{2}$ Department of General Surgery,

Rui Jin Hospital, ${ }^{3}$ Department of

Pathology, Shanghai Children's

Hospital, Shanghai Jiao Tong University,

Shanghai, People's Republic of China
Correspondence: Zhibao Lv

Department of General Surgery, Shanghai Children's Hospital, Shanghai Jiao Tong University, 355 Luding Road, Shanghai 200062, People's Republic of China

Tel +86 2I 52976067

Fax +86 2I 52976067

Email zhibao-lv@hotmail.com

\begin{abstract}
Solitary fibrous tumor (SFT) of the pancreas is rare, with 15 adult cases reported in the English literature. We described a 14-month-old boy who presented with obstructive jaundice. Dominantly elevated serum CA19-9 was detected. Imaging studies revealed a well-circumscribed, solid mass in the pancreatic head. A pancreaticoduodenectomy (child procedure) was performed using Shen's anastomosis technique. After resection of the tumor, liver function and serum tumor markers normalized and clinical signs receded. The boy was disease free after a follow-up of 12 months. Histological examination showed the tumor consisted of "patternless pattern" arranged spindle tumor cells and keloid-like hyalinized collagen. Immunohistochemical staining was positive for CD34 and vimentin. Mutation analysis of CTNNB1 was negative. To the best of our knowledge, our patient was the first case of pancreatic SFT in a pediatric population. SFT should be considered in differential diagnosis when confronted with a pancreatic tumor in children. Complete resection should be meticulously pursued.
\end{abstract}

Keywords: pancreas, rare tumors, children, rare pediatric tumors

\section{Introduction}

Solitary fibrous tumor (SFT) arising in the pancreas is extremely rare, usually occurring in the pleura. ${ }^{1}$ To date, all 15 reported pancreatic primary SFTs in the English literature are adult patients with a median age of 54 years. $^{2-16}$ Here, we describe an SFT of the pancreas in a 14-month-old boy managed by pancreaticoduodenectomy (PD), with histopathological analysis and a review of the literature.

\section{Case report}

Written informed consent was obtained from the patient's parents to have the case details and any accompanying images published. A 14-month-old boy presented with a 1-week history of painless jaundice, dark urine, and acholic stool. He had no fever, nausea, emesis, diarrhea, abdominal mass, or weight loss. Physical examination was unremarkable except icteric sclera. There was no history of hypoglycemia, and the patient's random blood glucose level was within the normal range. Family history was negative for tumors or diabetes. His serum laboratory results were significant: slightly decreased hemoglobin $(104 \mathrm{~g} / \mathrm{L}$, reference range: $110-160 \mathrm{~g} / \mathrm{L})$, hematocrit $(32.1 \%$, reference range: $34 \%-48 \%)$, elevated total bilirubin $(64.63 \mu \mathrm{mol} / \mathrm{L}$, reference range: 3.4-17.1 $\mu \mathrm{mol} / \mathrm{L})$, direct bilirubin $(39.0 \mu \mathrm{mol} / \mathrm{L}$, reference range: 0-6.8 $\mu \mathrm{mol} / \mathrm{L})$, alanine aminotransferase (431 U/L, reference range: 5-40 U/L), aspartate 
aminotransferase (467 U/L, reference range: 8-40 U/L), gamma-glutamyl transpeptidase $(1,218 \mathrm{U} / \mathrm{L}$, reference range: 11-50 U/L), and alkaline phosphatase (2,190 U/L, reference range: 0-500 U/L). Elevated serum CA19-9 was detected (268 U/mL, reference range: 0-35 U/mL), while other tumor markers including AFP, CEA, CA125, CA15-3, and NSE were within normal limits.

Abdominal ultrasonography revealed a well-demarcated hypoechoic solid mass with a diameter of $2.0 \mathrm{~cm}$ in the head of the pancreas. The mass showed slight hypoattenuation on unenhanced computed tomography (CT), with heterogeneous enhancement on the arterial phase after contrast injection (Figure 1). There was also mass effect on the duodenum and obstruction of the common bile duct (dilated gallbladder, dilatation of both intrahepatic and extrahepatic bile ducts). The mass was hypointense on T1-weighted magnetic resonance imaging (MRI) and heterogeneous-intense on T2-weighted MRI. Magnetic resonance cholangiopancreatography (MRCP) demonstrated slight dilatation of the main pancreatic duct (with a diameter of $2.5 \mathrm{~mm}$ ). Regional lymphadenopathy and distant metastasis (liver, brain, lung, bone, bone marrow) was not noted.

The patient was taken to surgery. Tumor biopsy was interpreted as mesenchymal origin on frozen analysis. A PD and cholecystectomy was performed using Shen's anastomosis technique. ${ }^{17}$ In brief, the pancreas was dissected according to the classical procedure. Then the pancreatic duct was identified by inspection and a probe (assisted by magnifying loupes), with a $3 \mathrm{~F}$ internal stent for draining the pancreatic juice. Clear tissue planes between the tumor and the pancreatic parenchyma were established. After removal of the specimen, reconstruction of the digestive system was performed in the following sequence (child procedure): endto-side duct-to-mucosal pancreaticojejunostomy, end-to-side choledochojejunostomy, and end-to-side gastrojejunostomy. A Roux jejunal loop was used for biliopancreatic anastomosis via the retrocolic route. The details of Shen's whole-layer tightly appressed technique (pancreaticojejunostomy) have been recently reported by our group. No drainage was placed and there was no blood transfusion during the operation.
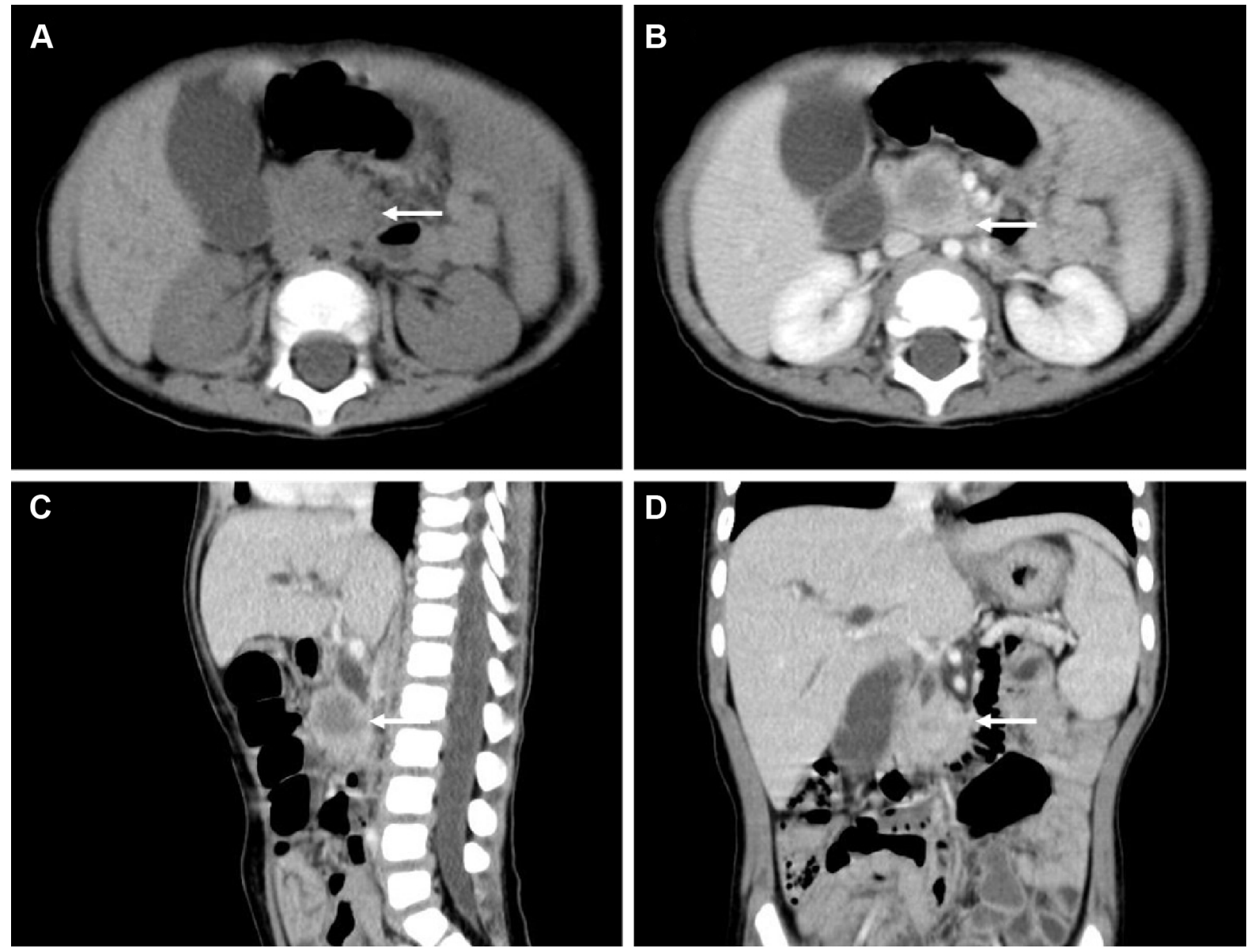

Figure I Abdominal computed tomography findings.

Notes: Computed tomography scan showing a well-demarcated tumor (arrows) in the pancreas head, with heterogeneous enhancement: axial view (A) and intravenous contrast-enhanced axial (B), sagittal (C), and coronal (D) views. 
Feeding was started on the 7th day after surgery. Postoperative recovery was uneventful, with no complications such as pancreatic fistula, biliary fistula, hemorrhage, intraabdominal infection, and wound infection being observed. No adjuvant chemotherapy or radiotherapy was given. After surgery (1 month), the liver function and serum tumor markers normalized and clinical signs (jaundice) receded. Abdominal CT scan performed at 6 months after resection revealed no recurrence. The boy was well and disease free within a follow-up of 12 months.

\section{Histopathological and molecular characteristics}

The mass appeared grossly well-circumscribed and noncapsulated with yellowish-gray cut surface (Figure 2A). The stomach, duodenum, proximal jejunum, and distal bile duct were macroscopically normal. The resected specimen was fixed in $10 \%$ buffered formalin, paraffin-embedded, microtome sectioned at $3 \mu \mathrm{m}$, and stained with hematoxylin and eosin. Genomic DNA was extracted from paraffin-embedded materials using a commercial kit (QIAamp DNA Mini Kit, Qiagen NV, Venlo, the Netherlands). Mutation analysis of CTNNB1 was performed by sequencing the polymerase chain reaction amplification products of exon 3. Immunohistochemistry (IHC) and mutation analysis (DNA isolation, amplification, purification, and sequencing) were performed as we previously reported. ${ }^{18,19}$ Sections were examined by an experienced pathologist (X Wang). Histological examination revealed the tumor consisted of "patternless pattern" arranged spindle tumor cells and keloid-like hyalinized collagen (Figure 2B). A mild to moderate degree of nuclear pleomorphism and a few atypical mitotic figures (2-5 per 10 high-power fields) were noted in the hypercellular area. The submucosa of the duodenum was microscopically infiltrated (Figure 2C). No tumor necrosis or vascular invasion was found. Ten regional lymph nodes were tumor free. IHC revealed that the tumor cells were strongly positive for CD34 (Figure 2D) and vimentin, focally positive for SMA, and negative for CD117, CD99, CD56, NSE, ALK, EMA, DES, S-100, MYOG, CEA, SYP, CgA, BCL-2, and CK.
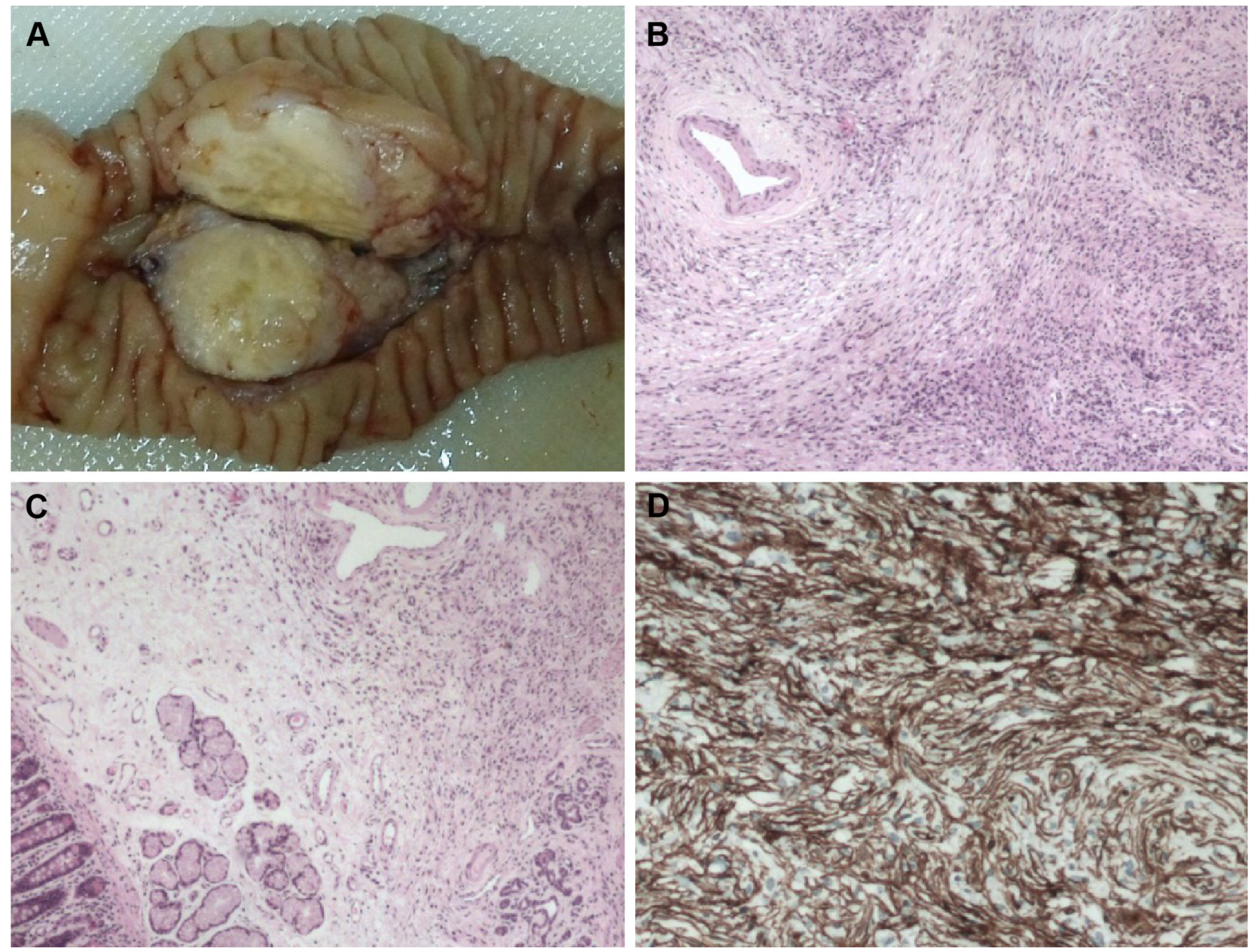

Figure 2 Histopathology of the pancreatic tumor.

Notes: Gross pathology showing a yellowish-gray, firm, well-circumscribed tumor (A). Histological findings showing "patternless pattern" arranged spindle tumor cells and thick collagen $(B)$ (original magnification $\times 40$ ), and infiltration of the submucosa of the duodenum $(\mathbf{C})$ (original magnification $\times 40)$. Immunohistochemical staining demonstrating strong CD34 positivity (D) (original magnification $\times 100$ ). 
The proliferation-associated $\mathrm{Ki}-67$ index was $<3 \%$. The result of sequencing was wild type. Based on histopathology and mutation analysis, a diagnosis of SFT with low grade malignancy was suggested.

\section{Discussion}

Primary mesenchymal tumor of the pancreas is a very rare entity both in adults and children, representing only $0.3 \%$ of surgically resected or biopsy-examined pancreatic tumor cases. $^{20,21}$ Reported benign or borderline pancreatic mesenchymal tumors include schwannoma, hamartoma, inflammatory myofibroblastic tumor, aggressive fibromatosis (also known as desmoid tumor), and lymphangioma/hemangioma. Malignant pancreatic mesenchymal tumors include rhabdomyosarcoma, Ewing sarcoma/primitive neuroectodermal tumor, lymphosarcoma, malignant fibrous histiocytoma, and undifferentiated/ unclassified sarcoma. Most of them are case reports or small series. ${ }^{22-25}$ SFT was formerly considered to be exclusively of pleural origin; however, many extra-thoracic sites of SFT have now been reported. ${ }^{1,26}$ Primary SFT arising in the pancreas is exceedingly rare. In the current study, we reported the first case of pancreatic SFT in a pediatric population.

A review of the English literature revealed 15 pancreatic SFT cases (Table 1, including the current case). The median age of the 16 patients was 53.5 years (range: 1-78 years). The ratio of female to male was 13:3. Almost half of patients presented with symptoms such as abdominal pain, abdominal distension, back pain, weight loss, and jaundice. The remaining tumors were found incidentally. The median size of tumor was $4.3 \mathrm{~cm}$ (range: $1.5-18.5 \mathrm{~cm}$ ). At ultrasonography, SFT was typically well-defined and hypoechoic. ${ }^{3,27}$
On unenhanced CT scans, SFT was nearly iso-attenuated or slightly hypo-attenuated to pancreas, and there was progressive enhancement on arterial phase and portal venous phase. The attenuation likely depended on the content of collagen. At MRI, SFT was hypointense on T1-weighted images and hyperintense or variable on T2-weighted images. No or slight dilatation of main pancreatic duct was found on MRCP. There was no significant ${ }^{18} \mathrm{~F}$-fluorodeoxyglucose uptake of the tumor observed on positron emission tomography/CT. Neuroendocrine tumor was always suggested based on imaging findings. No definitive cytologic diagnosis or only mesenchymal origin was established after fine needle aspiration due to cellular paucity. Estrella et al ${ }^{14}$ and VallatDecouvelaere et $\mathrm{al}^{28}$ have discussed histologic features of malignant SFTs in detail. Fibromatosis has considerable histologic overlap with SFT. High frequency of CTNNB1 heterozygous mutations (D32G, T41A, S45P, S45F, S45C, and in-frame deletion) has been reported by many groups. ${ }^{29-32}$ These mutations prevent phosphorylation and degradation of CTNNB1, resulting in increased nuclear CTNNB1 accumulation and transcriptional activation of target genes. No mutation was detected in our study.

Radical surgical resection remains the gold standard of treatment, even in histopathology-approved malignant cases. Enucleation of the mass with clear margins has been achieved in three cases in the literature. PD is rarely performed in children, and this unfamiliarity is associated with a significant risk of postoperative mortality and morbidity. ${ }^{33}$ However, d'Ambrosio et $\mathrm{al}^{34}$ reported favorable outcomes after PD for malignancies in children. To reduce postoperative complications such as pancreatic fistula, a new

Table I Clinicopathological characteristics of pancreatic solitary fibrous tumor in English literature

\begin{tabular}{|c|c|c|c|c|c|c|}
\hline Author & Age & Sex & Presentation & Location & Treatment & Outcome \\
\hline Lüttges et $\mathrm{al}^{2}$ & 50 & $\mathrm{~F}$ & Incidental finding & Body & Distal pancreatectomy & Good \\
\hline Miyamoto et $\mathrm{al}^{3}$ & 41 & $\mathrm{~F}$ & Abdominal pain & Neck & Laparoscopic enucleation & Good \\
\hline Srinivasan et $\mathrm{al}^{4}$ & 78 & $\mathrm{~F}$ & Back pain, weight loss & Body & Distal pancreatectomy & Good \\
\hline Kwon et $\mathrm{al}^{5}$ & 54 & $M$ & Incidental finding & Body & Median segmentectomy & Good \\
\hline Chetty et $\mathrm{al}^{6}$ & 67 & $\mathrm{~F}$ & Incidental finding & Uncinate process & PD & Good \\
\hline Sugawara et $\mathrm{al}^{7}$ & 55 & $\mathrm{~F}$ & Incidental finding & Head & PD & Good \\
\hline Santos et $\mathrm{al}^{8}$ & 40 & $\mathrm{~F}$ & Incidental finding & Body & Partial pancreatectomy & NA \\
\hline van der Vorst et al $^{9}$ & 67 & $\mathrm{~F}$ & Abdominal pain & Uncinate process & Enucleation & NA \\
\hline Tasdemir et al ${ }^{10}$ & 24 & $\mathrm{~F}$ & Abdominal pain & Head & Enucleation & Good \\
\hline Chen et $\mathrm{al}^{\prime \prime}$ & 49 & $\mathrm{~F}$ & Abdominal pain & Head & $\mathrm{PD}$ & Good \\
\hline Hwang et $\mathrm{al}^{12}$ & 53 & $\mathrm{~F}$ & Incidental finding & Head & Pancreatic head resection & Good \\
\hline Baxter et $\mathrm{al}^{13}$ & 58 & $\mathrm{~F}$ & Abdominal pain & Head & PD & Good \\
\hline Han et $\mathrm{al}^{15}$ & 77 & $\mathrm{~F}$ & Jaundice & Head & Biopsy & Alive \\
\hline Estrella et $\mathrm{al}^{14}$ & 52 & $\mathrm{~F}$ & Jaundice & Head & PD & Good \\
\hline Paramythiotis et $\mathrm{al}^{16}$ & 55 & $M$ & Incidental finding & Body & Distal pancreatectomy & Good \\
\hline Current study & 1 & $M$ & Jaundice & Head & PD & Good \\
\hline
\end{tabular}

Abbreviations: PD, pancreaticoduodenectomy; NA, not available; F, female; M, male. 
anastomotic method (Shen's whole-layer tightly appressed anastomosis technique) was introduced in the current case. The operation was tolerated well, and the postoperative course was uneventful. Impaired pancreatic endocrine function and atrophic changes of the pancreatic remnants after long-term follow-up have been observed by Sugito et al. ${ }^{35}$ Surgeons should be aware of possible pancreatic endocrine insufficiency and morphological changes when performing pancreaticojejunal anastomosis in children.

\section{Conclusion}

To the best of our knowledge, our patient was the first case of pancreatic SFT in children. SFT should be borne in mind when confronted with a tumor in the pancreas. Complete excision, even at the risk of aggressive resection, is meticulously pursued. Although the boy in the present study seems to have been cured without postoperative morbidity, longterm follow-up is warranted.

\section{Disclosure}

The authors report no conflicts of interest in this work.

\section{References}

1. Gold JS, Antonescu CR, Hajdu C, et al. Clinicopathologic correlates of solitary fibrous tumors. Cancer. 2002;94(4):1057-1068.

2. Lüttges J, Mentzel T, Hübner G, Klöppel G. Solitary fibrous tumour of the pancreas: a new member of the small group of mesenchymal pancreatic tumours. Virchows Arch. 1999;435(1):37-42.

3. Miyamoto H, Molena DA, Schoeniger LO, Haodong Xu. Solitary fibrous tumor of the pancreas: a case report. Int J Surg Pathol. 2007; 15(3):311-314.

4. Srinivasan VD, Wayne JD, Rao MS, Zynger DL. Solitary fibrous tumor of the pancreas: case report with cytologic and surgical pathology correlation and review of the literature. JOP. 2008;9(4):526-530.

5. Kwon HJ, Byun JH, Kang J, Park SH, Lee MG. Solitary fibrous tumor of the pancreas: imaging findings. Korean J Radiol. 2008;9 Suppl: S48-S51.

6. Chetty R, Jain R, Serra S. Solitary fibrous tumor of the pancreas. Ann Diagn Pathol. 2009;13(5):339-343.

7. Sugawara Y, Sakai S, Aono S, et al. Solitary fibrous tumor of the pancreas. Jpn J Radiol. 2010;28(6):479-482.

8. Santos LA, Santos VM, Oliveira OC, De Marco M. Solitary fibrous tumour of the pancreas: a case report. An Sist Sanit Navar. 2012;35(1): 133-136.

9. van der Vorst JR, Vahrmeijer AL, Hutteman M, et al. Near-infrared fluorescence imaging of a solitary fibrous tumor of the pancreas using methylene blue. World J Gastrointest Surg. 2012;4(7):180-184.

10. Tasdemir A, Soyuer I, Yurci A, Karahanli I, Akyildiz H. A huge solitary fibrous tumor localized in the pancreas: a young women. JOP 2012;13(3):304-307.

11. Chen JW, Lü T, Liu HB, et al. A solitary fibrous tumor in the pancreas. Chin Med J (Engl). 2013;126(7):1388-1389.

12. Hwang J, Kim J, Chang J. Imaging findings of a solitary fibrous tumor in pancreas: a case report. J Korean Soc Radiol. 2014;70(1):53-57.

13. Baxter AR, Newman E, Hajdu CH. Solitary fibrous tumor of the pancreas. J Surg Case Rep. 2015;2015(12).

14. Estrella JS, Wang H, Bhosale PR, Evans HL, Abraham SC. malignant solitary fibrous tumor of the pancreas. Pancreas. 2015;44(6):988-994.
15. Han S, Baek Y, Han S, et al. Solitary fibrous tumor of the pancreas: a case report and review of the literature. Korean J Med. 2015;88(3): 293-298.

16. Paramythiotis D, Kofina K, Bangeas P, Tsiompanou F, Karayannopoulou G, Basdanis G. Solitary fibrous tumor of the pancreas: Case report and review of the literature. World J Gastrointest Surg. 2016;8(6):461-466.

17. Zhang T, Wang X, Huo Z, et al. Shen's whole-layer tightly appressed anastomosis technique for duct-to-mucosa pancreaticojejunostomy in pancreaticoduodenectomy. Med Sci Monit. 2016;22:540-548.

18. Sheng Q, Lv Z, Xu W, et al. A case report of adrenocortical adenoma mimicking congenital adrenal hyperplasia in a young girl. Medicine (Baltimore). 2015;94(25):e1046.

19. Sheng Q, Lv Z, Xu W, Liu J, Wu Y, Shi J, Xi Z. Short- term surgical outcomes of preterm infants with necrotizing enterocolitis: A single-center experience. Medicine (Baltimore). 2016;95(30):e4379.

20. Johnson PR, Spitz L. Cysts and tumors of the pancreas. Semin Pediatr Surg. 2000;9(4):209-215.

21. Liu Z, Dong C, Wang C, Liu Q, Sun D, Wang L. Mixed acinar-endocrine carcinoma of pancreas: A case report and brief review of the literature. Onco Targets Ther. 2015;8:1633-1642.

22. Grosfeld JL, Vane DW, Rescorla FJ, McGuire W, West KW. Pancreatic tumors in childhood: analysis of 13 cases. J Pediatr Surg. 1990;25(10): 1057-1062.

23. Shorter NA, Glick RD, Klimstra DS, Brennan MF, Laquaglia MP Malignant pancreatic tumors in childhood and adolescence: The Memorial Sloan-Kettering experience, 1967 to present. J Pediatr Surg. 2002;37(6):887-892.

24. Yu DC, Kozakewich HP, Perez-Atayde AR, Shamberger RC, Weldon CB. Childhood pancreatic tumors: a single institution experience. J Pediatr Surg. 2009;44(12):2267-2272.

25. Nasher O, Hall NJ, Sebire NJ, de Coppi P, Pierro A. Pancreatic tumours in children: diagnosis, treatment and outcome. Pediatr Surg Int. 2015; 31(9):831-835.

26. Cranshaw IM, Gikas PD, Fisher C, Thway K, Thomas JM, Hayes AJ. Clinical outcomes of extra-thoracic solitary fibrous tumours. Eur J Surg Oncol. 2009;35(9):994-998.

27. Ginat DT, Bokhari A, Bhatt S, Dogra V. Imaging features of solitary fibrous tumors. AJR Am J Roentgenol. 2011;196(3):487-495.

28. Vallat-Decouvelaere AV, Dry SM, Fletcher CD. Atypical and malignant solitary fibrous tumors in extrathoracic locations: evidence of their comparability to intra-thoracic tumors. Am J Surg Pathol. 1998;22(12): 1501-1511.

29. Dômont J, Salas S, Lacroix L, et al. High frequency of beta-catenin heterozygous mutations in extra-abdominal fibromatosis: a potential molecular tool for disease management. Br J Cancer. 2010;102(6): $1032-1036$.

30. Tsukamoto $Y$, Imakita M, Nishitani A, Ito T, Izukura M, Hirota S. Pancreatic desmoid-type fibromatosis with beta-catenin gene mutationReport of a case and review of the literature. Pathol Res Pract. 2016; 212(5):484-489.

31. Tejpar S, Nollet F, Li C, et al. Predominance of beta-catenin mutations and beta-catenin dysregulation in sporadic aggressive fibromatosis (desmoid tumor). Oncogene. 1999;18(47):6615-6620.

32. Lazar AJ, Tuvin D, Hajibashi S, et al. Specific mutations in the betacatenin gene (CTNNB1) correlate with local recurrence in sporadic desmoid tumors. Am J Pathol. 2008;173(5):1518-1527.

33. Gouma DJ, van Geenen RC, van Gulik TM, et al. Rates of complications and death after pancreaticoduodenectomy: risk factors and the impact of hospital volume. Ann Surg. 2000;232(6):786-795.

34. d'Ambrosio G, del Prete L, Grimaldi C, et al. Pancreaticoduodenectomy for malignancies in children. J Pediatr Surg. 2014;49(4):534-538.

35. Sugito K, Furuya T, Kaneda H, et al. Long-term follow-up of nutritional status, pancreatic function, and morphological changes of the pancreatic remnant after pancreatic tumor resection in children. Pancreas. 2012; 41(4):554-559. 


\section{Publish your work in this journal}

OncoTargets and Therapy is an international, peer-reviewed, open access journal focusing on the pathological basis of all cancers, potential targets for therapy and treatment protocols employed to improve the management of cancer patients. The journal also focuses on the impact of management programs and new therapeutic agents and protocols on

patient perspectives such as quality of life, adherence and satisfaction. The manuscript management system is completely online and includes a very quick and fair peer-review system, which is all easy to use. Visit http://www.dovepress.com/testimonials.php to read real quotes from published authors.

Submit your manuscript here: http://www.dovepress.com/oncotargets-and-therapy-journal 